\title{
Retrospective review of superficial femoral artery stenting in diabetic patients: thiazolidinedione use may decrease reinterventions
}

\author{
Karen L Walker, Daniel B Walsh, Philip P Goodney, Samantha A Connell, David H Stone, Richard J Powell
} and Eva M Rzucidlo*

\begin{abstract}
Background: Diabetics are known to have inferior outcomes following peripheral vascular interventions. Thiazolidinediones are oral diabetic agents which improve outcomes following coronary bare metal stenting. No studies have been performed evaluating thiazolidinedione use and outcomes following lower extremity endovascular interventions. We hypothesize that diabetic patients taking thiazolidinediones at the time of primary superficial femoral artery (SFA) stenting have fewer reinterventions.

Methods: A retrospective review was performed to identify diabetic patients undergoing primary SFA stenting. The unit of analysis was the extremity. The primary outcome was freedom from target lesion revascularization stratified by thiazolidinedione use, evaluated by Kaplan Meier curves and a log rank test. A Cox proportional hazards model was constructed to determine variables associated with freedom from target lesion revascularization.

Results: SFA stents were placed in 138 extremities in 128 diabetic patients between August 1, 2001 and July 15, 2012. Twenty-four patients were taking thiazolidinediones at the time of SFA stenting. All patients taking thiazolidinediones had TASC A or B lesions. Twenty-seven extremities in the non-thiazolidinedione group had TASC C or D lesions and were excluded to control for disease severity. Freedom from target lesion revascularization was significantly higher in diabetics taking thiazolidinediones at 2 years, $88.5 \%$ vs. 59.4\%, $\mathrm{P}=0.02$, SE $<10 \%$. Cox modeling identified a protective trend for thiazolidinedione use (thiazolidinedione use HR 0.33, 95\% CI 0.09-1.13), whereas critical limb ischemia and insulin use were associated with trends for worse freedom from target lesion revascularization.

Conclusions: This pilot, translation study demonstrates that diabetic patients taking thiazolidinediones at the time of primary SFA stenting have decreased reintervention rates at 2 years. These results may be explained by higher adiponectin levels or other anti-inflammatory effects in patients taking thiazolidinedione. National and regional quality improvement registries should consider collecting information regarding specific diabetic regimens and use of PPAR agonists such as cilostazol and fibrates.
\end{abstract}

Keywords: Adiponectin, Diabetes, Peripheral arterial disease, Thiazolidinediones, Endovascular

\footnotetext{
* Correspondence: eva.m.rzucidlo@hitchcock.org

Section of Vascular Surgery, Dartmouth Hitchcock Medical Center, 1 Medical
} Center Drive, Lebanon, NH 03756, USA 


\section{Background}

Superficial femoral artery (SFA) stenting has revolutionized the care provided to patients with lower extremity peripheral artery disease and is a commonly performed procedure [1]. Diabetes is a known risk factor for poor clinical outcomes, such as recurrent claudication, decrease in ankle-brachial index or failure to heal a wound [1-4]. Poor clinical outcomes following SFA stenting frequently result in reintervention to correct in-stent restenosis, narrowing of the stented arterial segment.

The reasons why diabetics are at increased risk for developing in-stent restenosis are largely unknown. However, studying clinical outcomes associated with specific medication regimens may prove useful. For example, prior studies have identified that use of exogenous insulin is a risk factor for restenosis following endovascular intervention in the coronary and peripheral circulations $[2,5,6]$. Alternatively, use of thiazolidinediones (TZDs) has been associated with decreased rates of in-stent restenosis for coronary bare metal stents [7-9].

While the association between TZD use and outcomes has been studied for patients undergoing coronary interventions, there is no data available for patients undergoing interventions for low extremity peripheral arterial disease. Therefore, we studied the association between TZD use and reintervention rate for diabetic patients undergoing SFA stenting. Our results demonstrate that the rate of reintervention was significantly lower in diabetics taking TZDs versus diabetics not taking TZDs at 2 years, $88.5 \%$ vs. $59.4 \%, \mathrm{P}=0.02, \mathrm{SE}<10 \%$.

\section{Methods}

We searched the vascular surgery database for elective SFA stents between August 1, 2001 and August 15, 2012 [3]. The analysis includes only diabetics undergoing primary interventions. Diabetics who were not taking medications for glycemic control were excluded from our analysis $(\mathrm{n}=13)$ (Figure 1$)$.

Diabetic patients were stratified by TZD use. Freedom from target lesion revascularization (TLR) was evaluated. After placement of an SFA stent, patients were evaluated at 1, 6, and 12 months and then yearly. Recurrent symptoms, decreased ankle brachial index, or a stenosis identified by arterial duplex with greater than a $2.5 \times$ step-up in peak systolic velocity prompted further investigation.

Patient demographics, comorbidities, and peripheral arterial disease severity characteristics were analyzed using Student's t-test, chi square, and Fisher's exact test. Chronic kidney disease was defined as creatinine $>1.6$. Kaplan Meier survival curves using the peto method were created to test for differences in freedom from TLR.

A Cox proportional hazards model was created to identify predictors of freedom from TLR. Variables with a $\mathrm{P}<0.2$ in univariate testing were included in a Cox

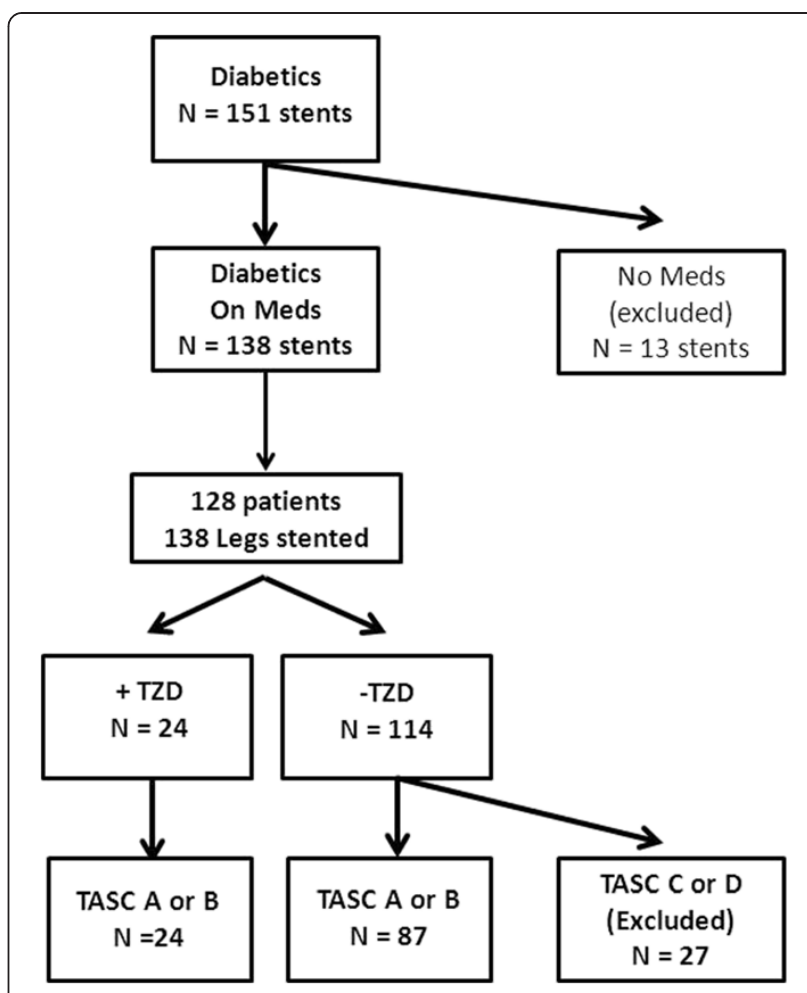

Figure 1 Cohort description. Cohort exclusion criteria are depicted.

proportional hazards model, and backwards stepwise elimination was used to remove non-significant variables. The statistical analysis was performed using STATA 12.1.

The Committee for the Protection of Human Subjects at our institution granted institutional review board approval for this study.

\section{Results}

Between August 1st 2001 and July 15th 2012, the vascular surgeons at our institution performed 363 primary SFA stenting procedures. Of these, 128 diabetic patients who were taking diabetic medications underwent SFA stenting in 138 extremities (Figure 1). Demographics, comorbidities, and cardiovascular medication use were similar regardless of TZD use. Use of insulin, metformin, and sulfonylureas were also similar. However, significant differences related to disease severity variables were present (Table 1). Specifically, all patients taking TZDs had either a TASC A or B lesion and the prevalence of critical limb ischemia (CLI) was significantly lower among the TZD group. Technical success was achieved in all cases. The mean stented vessel diameter was 5.4 mm (95\% CI: $5.3-5.5 \mathrm{~mm}$ ) for patients not taking TZDs vs. $5.5 \mathrm{~mm}$ (95\% CI: $5.2-5.8 \mathrm{~mm})$ for patients taking TZDs, $\mathrm{p}=0.39$. The mean stented length was $15.2 \mathrm{~cm}$ (95\% CI: 13.5-17.0 cm) for patients not taking TZDs vs. $8.9 \mathrm{~cm}(95 \% \mathrm{CI}: 6.6-11.2 \mathrm{~cm})$ for patients taking TZDs, $\mathrm{p}<0.01$. Stents grafts were used in 2 cases; these patients 
Table 1 Characteristics of diabetic patients undergoing SFA stenting

\begin{tabular}{lccc}
\hline & $+\mathbf{+ T X D}$ & $\mathbf{- T Z D}$ & P-value \\
& $\mathbf{N}=\mathbf{2 4}$ & $\mathbf{N}=\mathbf{1 1 4}$ & \\
\hline Age & 64.46 & 69.57 & 0.06 \\
Male & $79.17 \%$ & $54.39 \%$ & $\mathbf{0 . 0 3}$ \\
HTN & $91.67 \%$ & $88.60 \%$ & 0.66 \\
HLD & $79.17 \%$ & $81.58 \%$ & 0.78 \\
CAD & $54.17 \%$ & $54.39 \%$ & 0.98 \\
CKD & $13.39 \%$ & $14.91 \%$ & 0.76 \\
COPD & $4.17 \%$ & $11.93 \%$ & 0.26 \\
Current smoker & $12.50 \%$ & $22.81 \%$ & 0.26 \\
Statin & $62.50 \%$ & $69.03 \%$ & 0.53 \\
ASA & $78.26 \%$ & $79.44 \%$ & 0.9 \\
Plavix & $39.13 \%$ & $51.40 \%$ & 0.29 \\
Cilostazol & $8.70 \%$ & $14.02 \%$ & 0.49 \\
Insulin & $50.00 \%$ & $64.04 \%$ & 0.24 \\
Metformin & $37.50 \%$ & $35.09 \%$ & 0.82 \\
Sulfonylurea & $29.17 \%$ & $37.72 \%$ & 0.49 \\
CLI & $33.33 \%$ & $62.2 / 8 \%$ & $\mathbf{0 . 0 1}$ \\
TASC A or B & $100 \%$ & $76.32 \%$ & $\mathbf{0 . 0 1}$ \\
Preop toe pressure & 52.5 & 40.95 & 0.18 \\
3 Vessel outflow & $41.67 \%$ & $35.09 \%$ & 0.54 \\
\hline & & &
\end{tabular}

were not taking TZDs. Freedom from TLR was significantly higher for diabetics taking TZDs at 2 years, $88.5 \%$ vs. $61.2 \%, \mathrm{p}=0.02$ (Figure 2).

To address the concern that disease severity was different for those patients taking TZDs vs. those patients not taking TZDs, we performed a second analysis limited to diabetic patients with TASC A and B lesions
(Figure 1). This analysis excluded 27 patients with TASC $\mathrm{C}$ and $\mathrm{D}$ lesions who were not taking TZDs; therefore, 87 patients not taking TZDs and 24 patients taking TZDs were included in the cohort. Demographics, comorbidities, use of cardiovascular medications, and use of diabetic medications were similar for patients with TASC A and B lesions regardless of TZD use. However, the prevalence of CLI still remained lower for patients taking TZDs (Table 2). The mean stented vessel diameter was $5.4 \mathrm{~mm}(95 \% \mathrm{CI}: 5.2-5.5 \mathrm{~mm})$ for patients not taking TZDs vs. $5.5 \mathrm{~mm}$ (95\% CI: $5.2-$ $5.8 \mathrm{~mm}$ ) for patients taking TZDs, $\mathrm{p}=0.37$. The mean stented length was $12.7 \mathrm{~cm}(95 \% \mathrm{CI}: 11.0-14.3 \mathrm{~cm})$ for patients not taking TZDs vs. $8.9 \mathrm{~cm}$ (95\% CI: 6.6$11.2 \mathrm{~cm}$ ) for patients taking TZDs, $\mathrm{p}=0.02$. Despite the exclusion of TASC C and D lesions, the association of TZD use with improved freedom from TLR remained: patients with a TASC A or B lesion taking a TZD at the time of SFA stenting had a significantly better outcome with $88.5 \%$ vs. $59.5 \%$ being free from TLR at 2 years, $\mathrm{P}=0.02$ (Figure 3).

Finally, in our multivariable model, we found that among all diabetic patients $(\mathrm{n}=138)$, three variables were associated with freedom from TLR: CLI, insulin use and TZD use, with TZD use being protective (Table 3). However, the effect imparted by TZD use demonstrated only a trend towards significance in this pilot study.

\section{Discussion}

The goal of this pilot, translational study was to identify if TZD use is associated with improved TLR in diabetics undergoing SFA stenting. This study is the first to show that diabetics taking TZDs at the time of primary SFA stenting have a lower reintervention rate within the first

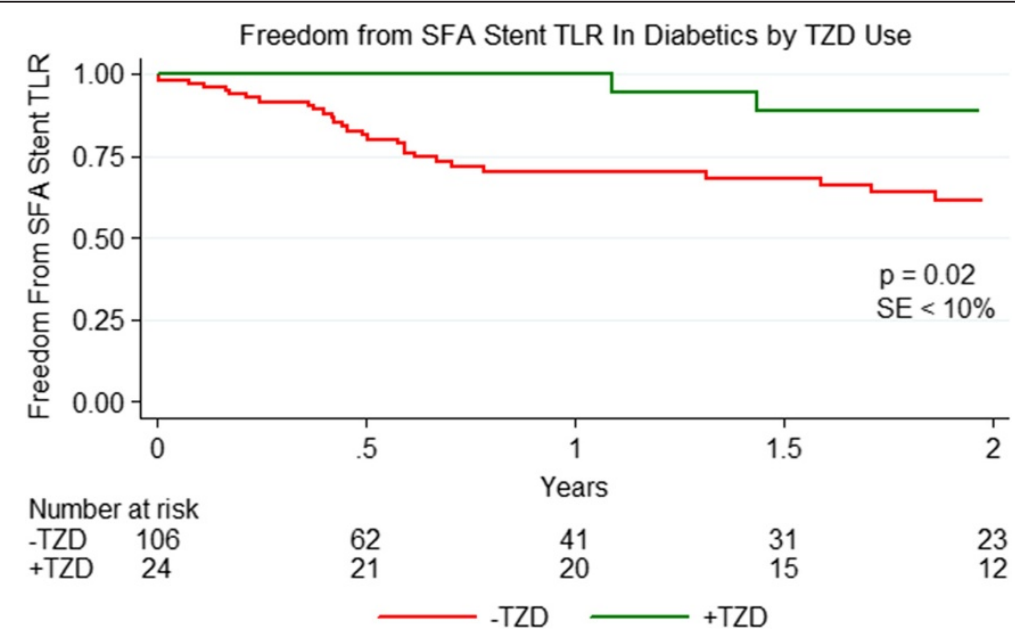

Figure 2 Freedom from SFA Stent TLR among all diabetics by TZD use. Freedom from TLR was $88.5 \%$ for diabetics taking thiazolidinediones at the time of SFA stenting vs. $61.2 \%$ for those not taking a thiazolidinedione at 2 years. This difference was statistically significant, $p=0.02$, with a standard error $<10 \%$ at all points on the graph. 
Table 2 Characteristics of diabetic patients with TASC A or B SFA lesions

\begin{tabular}{lccc}
\hline & $+\mathbf{+ T X D}$ & $\mathbf{- T Z D}$ & P-value \\
\hline Age & 64.45 & $\mathbf{N}=\mathbf{8 7}$ & \\
Male & $79.17 \%$ & 58.75 & 0.11 \\
HTN & $97.67 \%$ & $88.51 \%$ & $\mathbf{0 . 0 3}$ \\
HLD & $79.17 \%$ & $81.61 \%$ & 0.66 \\
CAD & $54.17 \%$ & $54.02 \%$ & 0.78 \\
CKD & $17.39 \%$ & $16.09 \%$ & 0.99 \\
COPD & $4.17 \%$ & $8.54 \%$ & 0.88 \\
Current smoker & $12.50 \%$ & $18.39 \%$ & 0.48 \\
Statin & $62.50 \%$ & 70.93 & 0.50 \\
ASA & $78.26 \%$ & $82.72 \%$ & 0.43 \\
Plavix & $39.13 \%$ & $44.44 \%$ & 0.63 \\
Cilostazol & $8.70 \%$ & $13.58 \%$ & 0.65 \\
Insulin & $50.00 \%$ & $68.97 \%$ & 0.53 \\
Metformin & $37.50 \%$ & $31.03 \%$ & 0.10 \\
Sulfonylurea & $27.17 \%$ & $31.03 \%$ & 0.62 \\
CLI & $33.33 \%$ & $60.92 \%$ & 0.81 \\
Preop toe pressure & 52.5 & 43.46 & $\mathbf{0 . 0 2}$ \\
3 vessel outflow & $41.67 \%$ & $37.21 \%$ & 0.32 \\
\hline
\end{tabular}

2 years. In our small cohort, none of the patients taking TZDs had reinterventions within the first year; the 2 reinterventions which were performed occurred between 12 and 18 months following the initial procedure. Despite the mean stented length being slightly longer for patients with TASC A and B lesions not taking TZDs $(12.7 \mathrm{~cm}$ vs $8.9 \mathrm{~cm})$, this difference likely does not explain our result as it is clinically insignificant.
Table 3 Cox proportional hazards model

\begin{tabular}{lllll}
\hline & Hazard ratio & Standard error & P-value & $\mathbf{9 5 \% ~ C l}$ \\
\hline CLI & 1.89 & 0.78 & 0.13 & $0.84-4.26$ \\
Insulin & 1.87 & 0.81 & 0.15 & $0.79-4.39$ \\
TZD & 0.33 & 0.21 & 0.08 & $0.09-1.13$ \\
\hline
\end{tabular}

Cox proportional hazards were performed to determine predictors of primary patency. Critical limb ischemia (CLI), insulin use, thiazolidinediones (TZD) use were identified as important variables.

Although our Cox proportional hazards model only trended towards statistical significance, the model identified TZD use as a protective factor associated with improved TLR, supporting our Kaplan Meier analysis. The model also identified CLI and insulin use as predictors of worse freedom from TLR which is consistent with prior studies $[2,3]$. The main limitations of our model were small cohort size and low number of failures. Despite these limitations, this model is likely reliable and should be tested in a larger cohort of patients.

The results from this study are consistent with data from the cardiology literature demonstrating that TZD use is protective against in-stent restenosis in the coronary circulation among diabetic patients [7-9]. Surprisingly, even when nondiabetic patients were randomized to TZD use vs. placebo, TZD use resulted in decreased in-stent restenosis following bare metal coronary stenting [10]. One unexpected finding in our study was that all diabetic patients taking TZDs appeared to have less severe disease as exemplified by the presence of only TASC A or B lesions and a lower prevalence of CLI as an indication for stenting. Emerging data suggest that TZD use may help modulate the development of atherosclerosis. Review of the coronary artery disease literature identified preliminary data showing decreased

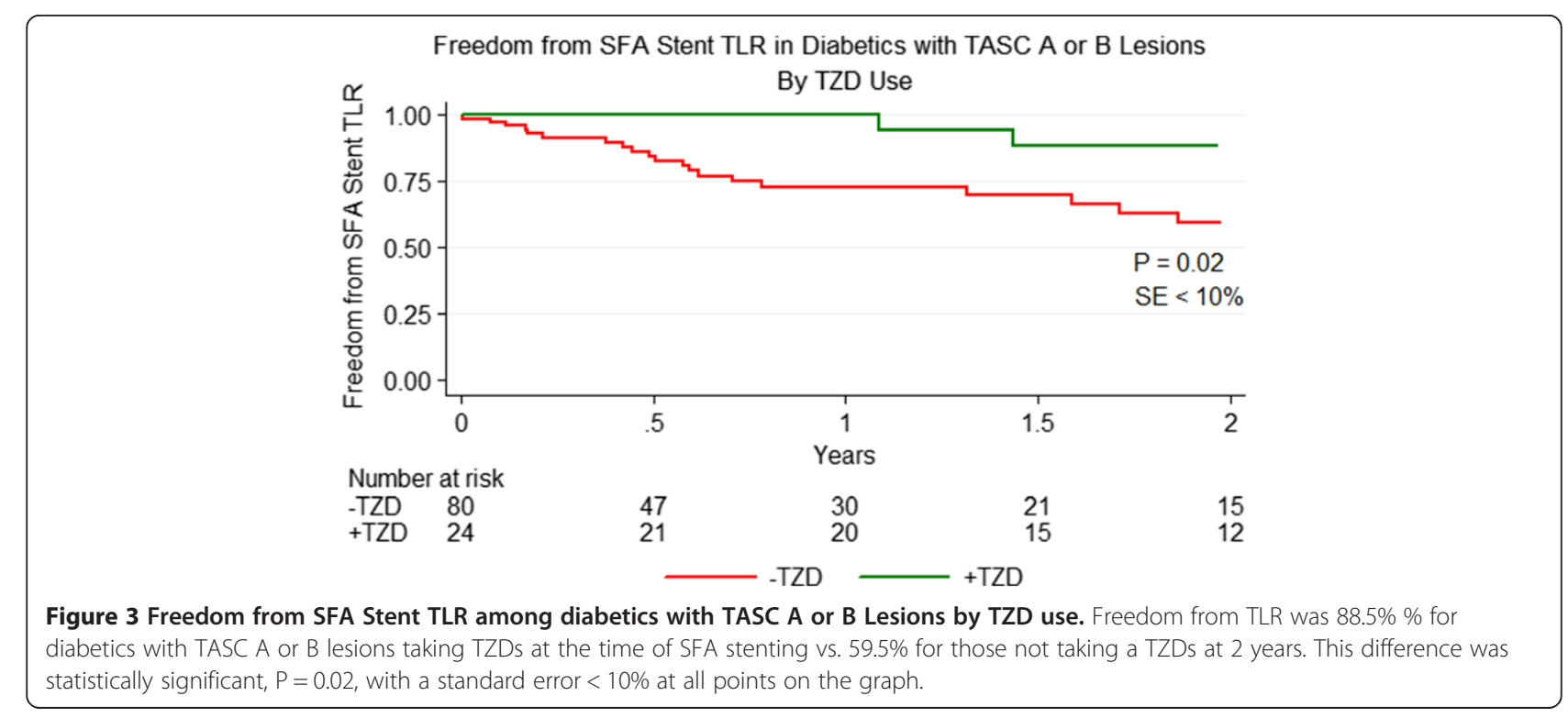


plaque burden following treatment with TZDs $[11,12]$. However, it is unknown if the same is true for lower extremity atherosclerosis.

The mechanism through which TZDs protect against in-stent restenosis is an area of active study. TZDs are peroxisome proliferator-activatory receptor-gamma (PPAR-gamma) agonists and have many effects: insulin sensitization, anti-proliferation via blocking cell cycle regulators, anti-platelet aggregation, and inhibition of inflammatory cytokines such as tumor necrosis factoralpha [13-16]. TZDs also enhance anti-inflammatory proteins such as adiponectin. Adiponectin is best known as an insulin sensitizing adipokine secreted from adipocytes. However, adiponectin is also secreted from VSMCs and affects VSMC phenotype which has implications for the development of in-stent restenosis [17].

VSMCs can exhibit two phenotypes: a proliferative phenotype, and a quiescent or nonproliferative phenotype [17]. In-stent restenosis develops after VSMCs adopt the proliferative phenotype allowing cells to proliferate and migrate inwards; this process is known as neointimal hyperplasia. We have demonstrated that adiponectin secretion by VSMCs promotes the nonproliferative phenotype of neighboring VSMCs in a paracrine manner [17]. Similarly, TZDs promote the nonproliferative VSMC phenotype via adiponectin secretion [18-20]. The protective effect of adiponectin against neointimal hyperplasia has also been demonstrated in animal models. Adiponectin knockout mice were shown to have increased neointimal hyperplasia following femoral artery wire injury versus wild type mice [21].

While specific mechanisms explaining the relationship between diabetes and propensity for in-stent restenosis have yet to be identified, the adiponectin pathway may be important as diabetics are known to have lower adiponectin levels than nondiabetics and higher rates of in-stent restenosis [22,23]. We hypothesize that our results are secondary to higher adiponectin levels in patients taking TZDs (Figure 4). Support for this hypothesis is derived from previous studies demonstrating that low plasma adiponectin levels prospectively predicted in-stent restenosis for coronary bare metal stents [24-27]. In order to test this hypothesis further, we are currently enrolling patients in a prospective study designed to examine the ability of pre-procedure adiponectin levels to predict outcomes following lower extremity stenting. If serum adiponectin level predicts lower extremity in-stent restenosis, then a low adiponectin level may be used to identify patients who would benefit from treatment with a PPAR agonist, such as cilostazol and fibrates [28,29].

Due to the retrospective nature of this study, several limitations exist. First, it is unknown why some patients were placed on TZDs and why others were not. The low

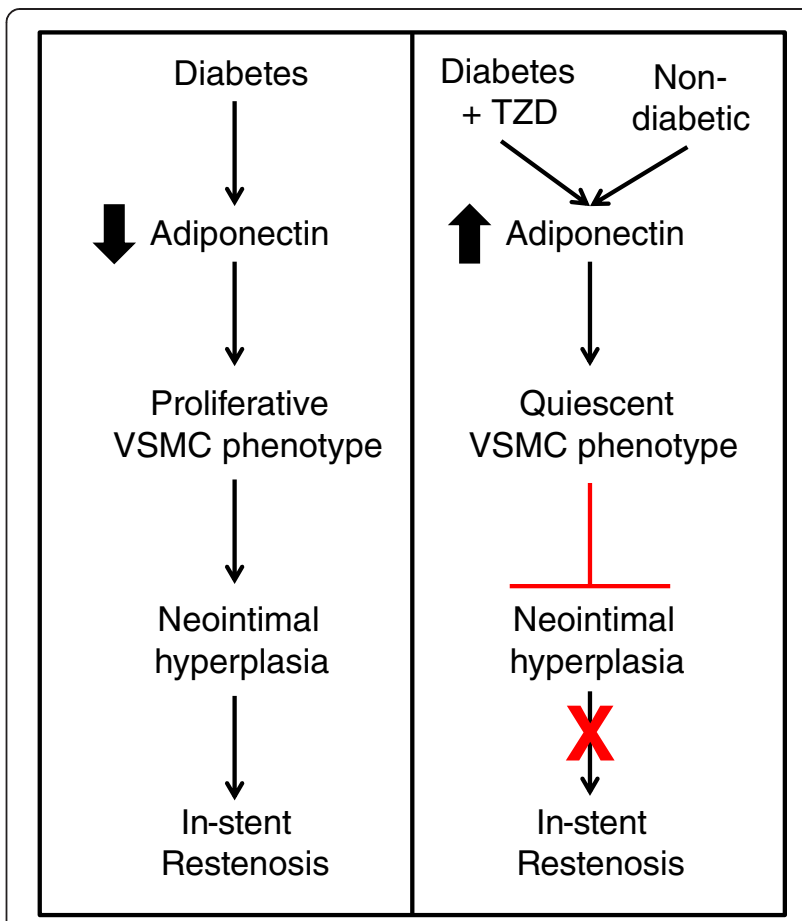

Figure 4 Proposed hypothesis-in-stent restenosis, diabetes, thiazolidinedione use, adiponectin, and vascular smooth muscle cell phenotype. The panel on the left proposes that diabetics are at increased risk for in-stent restenosis due to lower adiponectin levels increasing the likelihood that vascular smooth muscle cells (VSMCs) will adopt the proliferative phenotype. The panel on the right proposes that diabetics taking thiazolidinediones (TZDs) have higher adiponectin levels increasing the likelihood that vascular smooth muscle cells (VSMCs) will adopt the quiescent phenotype which decreases the chance of developing in-stent restenosis.

use of TZDs may be due to changes in practice patterns related to the FDA's recent black box warning regarding TZD use in patients with congestive heart failure [30]. Importantly, second generation TZDs are currently under development and have been reported to have a lower side effect profile [31]. Second, we were unable to control for hemoglobin A1c level; many of our patients receive primary care outside of our hospital system and therefore hemoglobin A1c was not consistently recorded in the medical record. Third, the study interval was relatively long which may raise concerns regarding changes in practice patterns. However, we evaluated TZD use and found it to be consistent across the study interval thereby decreasing this concern (data not shown).

\section{Conclusions}

This small pilot study suggests that TZD use is associated with decreased reinterventions following SFA stenting in diabetic patients; this result should be investigated further using larger databases. Higher adiponectin levels resulting from PPAR-gamma activation secondary to TZD use may be a potential explanation for our results. 
We are prospectively collecting serum at the time of SFA stenting in order to measure adiponectin levels and evaluate this hypothesis. Other anti-inflammatory effects secondary to TZD use may also explain our results. We would like to strongly encourage national and regional quality improvement registries to collect information regarding patient's specific diabetic regimens and use of PPAR agonists such as cilostazol and fibrates. Additional epidemiological data will help us better understand how to maximize medical management in diabetics undergoing endovascular intervention for peripheral arterial disease.

\section{Abbreviations}

CLI: Critical limb ischemia; PPAR-gamma: Peroxisome proliferator-activatory receptor-gamma; SFA: Superficial femoral artery; TASC: TransAtlantic Inter-Society Consensus; TLR: Target lesion revascularization; TZD: Thiazolidinedione.

\section{Competing interests}

The authors declare that they have no competing interests.

\section{Authors' contributions}

KLW contributed to the study conception and design, contributed to data collection, analysis and interpretation, and drafted the manuscript. DBW revised the manuscript critically for intellectual content. PPG contributed to data analysis and interpretation as well as editing the manuscript for intellectual content. DHS revised the manuscript critically for intellectual content. SO contributed to data collection and revised the manuscript critically for intellectual content. RJP revised the manuscript critically for intellectual content. EMR contributed to the study conception and design, contributed to data analysis and interpretation, and edited the manuscript for intellectual content. All authors read and approved the final manuscript.

Received: 28 September 2014 Accepted: 2 December 2014 Published: 11 December 2014

\section{References}

1. Hong MS, Beck AW, Nelson PR: Emerging national trends in the management and outcomes of lower extremity peripheral arterial disease. Ann Vasc Surg 2011, 25:44-54.

2. Bakken AM, Palchik E, Hart JP, Rhodes JM, Saad WE, Davies MG: Impact of diabetes mellitus on outcomes of superficial femoral artery endoluminal interventions. J Vasc Surg 2007, 46:946-958. discussion 958.

3. Scali ST, Rzucidlo EM, Bjerke AA, Stone DH, Walsh DB, Goodney PP, Chang CK, Powell RJ: Long-term results of open and endovascular revascularization of superficial femoral artery occlusive disease. J Vasc Surg 2011, 54:714-721.

4. lida O, Uematsu M, Soga Y, Hirano K, Suzuki K, Yokoi H, Muramatsu T, Inoue $\mathrm{N}$, Nanto S, Nagata S: Timing of the restenosis following nitinol stenting in the superficial femoral artery and the factors associated with early and late restenoses. Catheter Cardiovasc Interv 2011, 78:611-617.

5. Woudstra P, Damman P, Beijk MA, Grundeken MJ, Harskamp RE, Koch KT, Henriques JP, Baan J Jr, Vis MM, Piek JJ, Tijssen JG, de Winter RJ: Clinical outcomes after bare-metal stenting in diabetic patients with lesions carrying a low risk of restenosis. Catheter Cardiovasc Interv 2013, 81:26-33.

6. Moussa I, Leon MB, Baim DS, O'Neill WW, Popma JJ, Buchbinder M, Midwall J, Simonton CA, Keim E, Wang P, Kuntz RE, Moses JW: Impact of sirolimus-eluting stents on outcome in diabetic patients: a SIRIUS (SIRollmUS-coated Bx Velocity balloon-expandable stent in the treatment of patients with de novo coronary artery lesions) substudy. Circulation 2004, 109:2273-2278.

7. Choi D, Kim SK, Choi SH, Ko YG, Ahn CW, Jang Y, Lim SK, Lee HC, Cha BS: Preventative effects of rosiglitazone on restenosis after coronary stent implantation in patients with type 2 diabetes. Diabetes Care 2004, 27:2654-2660

8. Nishio K, Sakurai M, Kusuyama T, Shigemitsu M, Fukui T, Kawamura K, Itoh S, Konno N, Katagiri T: A randomized comparison of pioglitazone to inhibit restenosis after coronary stenting in patients with type 2 diabetes. Diabetes Care 2006, 29:101-106.
9. Takagi T, Yamamuro A, Tamita K, Yamabe K, Katayama M, Mizoguchi S, Ibuki M, Tani T, Tanabe K, Nagai K, Shiratori K, Morioka S, Yoshikawa J: Pioglitazone reduces neointimal tissue proliferation after coronary stent implantation in patients with type 2 diabetes mellitus: an intravascular ultrasound scanning study. Am Heart J 2003, 146:E5.

10. Marx N, Wohrle J, Nusser T, Walcher D, Rinker A, Hombach V, Koenig W, Hoher M: Pioglitazone reduces neointima volume after coronary stent implantation: a randomized, placebo-controlled, double-blind trial in nondiabetic patients. Circulation 2005, 112:2792-2798.

11. Ogasawara D, Shite J, Shinke T, Watanabe S, Otake H, Tanino Y, Sawada T, Kawamori H, Kato H, Miyoshi N, Hirata K: Pioglitazone reduces the necrotic-core component in coronary plaque in association with enhanced plasma adiponectin in patients with type 2 diabetes mellitus. Circ J 2009, 73:343-351.

12. Nakayama T, Komiyama N, Yokoyama M, Namikawa S, Kuroda N, Kobayash $Y$, Komuro I: Pioglitazone induces regression of coronary atherosclerotic plaques in patients with type 2 diabetes mellitus or impaired glucose tolerance: a randomized prospective study using intravascular ultrasound. Int J Cardiol 2010, 138:157-165.

13. Ceriello A: Thiazolidinediones as anti-inflammatory and anti-atherogenic agents. Diabetes Metab Res Rev 2008, 24:14-26.

14. Hupfeld CJ, Weiss RH: TZDs inhibit vascular smooth muscle cell growth independently of the cyclin kinase inhibitors p21 and p27. Am J Physiol Endocrinol Metab 2001, 281:E207-E216.

15. Bruemmer D, Law RE: Thiazolidinedione regulation of smooth muscle cell proliferation. Am J Med 2003, 115(Suppl 8A):87S-92S.

16. Fuentes E, Palomo I: Mechanism of antiplatelet action of hypolipidemic, antidiabetic and antihypertensive drugs by PPAR activation: PPAR agonists: new antiplatelet agents. Vasc Pharmacol 2014, 62:162-166.

17. Ding M, Carrao AC, Wagner RJ, Xie Y, Jin Y, Rzucidlo EM, Yu J, Li W, Tellides G, Hwa J, Aprahamian TR, Martin KA: Vascular smooth muscle cell-derived adiponectin: a paracrine regulator of contractile phenotype. $J \mathrm{Mo} / \mathrm{Cell}$ Cardiol 2012, 52:474-484.

18. de Dios ST, Bruemmer D, Dilley RJ, Ivey ME, Jennings GL, Law RE, Little PJ: Inhibitory activity of clinical thiazolidinedione peroxisome proliferator activating receptor-gamma ligands toward internal mammary artery, radial artery, and saphenous vein smooth muscle cell proliferation. Circulation 2003, 107:2548-2550.

19. Igarashi $M$, Hirata $A$, Yamaguchi $H$, Tsuchiya $H$, Ohnuma $H$, Tominaga $M$, Daimon M, Kato T: Characterization of an inhibitory effect of pioglitazone on balloon-injured vascular smooth muscle cell growth. Metabolism 2001, 50:955-962.

20. Igarashi M, Takeda Y, Ishibashi N, Takahashi K, Mori S, Tominaga M, Saito Y. Pioglitazone reduces smooth muscle cell density of rat carotid arterial intima induced by balloon catheterization. Horm Metab Res 1997, 29:444-449.

21. Matsuda M, Shimomura I, Sata M, Arita Y, Nishida M, Maeda N, Kumada M, Okamoto Y, Nagaretani H, Nishizawa H, Kishida K, Komuro R, Ouchi N, Kihara S, Nagai R, Funahashi T, Matsuzawa Y: Role of adiponectin in preventing vascular stenosis. The missing link of adipo-vascular axis. J Biol Chem 2002, 277:37487-37491.

22. Yu JG, Javorschi S, Hevener AL, Kruszynska YT, Norman RA, Sinha M, Olefsky JM: The effect of thiazolidinediones on plasma adiponectin levels in normal, obese, and type 2 diabetic subjects. Diabetes 2002, 51:2968-2974.

23. Hotta K, Funahashi T, Arita Y, Takahashi M, Matsuda M, Okamoto Y, Iwahashi H, Kuriyama H, Ouchi N, Maeda K, Nishida M, Kihara S, Sakai N, Nakajima T, Hasegawa K, Muraguchi M, Ohmoto Y, Nakamura T: Plasma concentrations of a novel, adipose-specific protein, adiponectin, in type 2 diabetic patients. Arterioscler Thromb Vasc Biol 2000, 20:1595-1599.

24. Moldoveanu E, Mut-Vitcu B, Tanaseanu GR, Marta DS, Manea G, Kosaka T, Vidulescu C, Tanaseanu C: Low basal levels of circulating adiponectin in patients undergoing coronary stenting predict in-stent restenosis, independently of basal levels of inflammatory markers: lipoprotein associated phospholipase A2, and myeloperoxidase. Clin Biochem 2008, 41:1429-1433

25. Nishimura M, Hashimoto T, Kobayashi H, Yamazaki S, Okino K, Fujita H, Inoue N, Takahashi H, Ono T: Association of the circulating adiponectin concentration with coronary in-stent restenosis in haemodialysis patients. Nephrol Dial Transplant 2006, 21:1640-1647.

26. Kitta Y, Takano H, Nakamura T, Kodama Y, Umetani K, Fujioka D, Saito Y, Kawabata K, Obata JE, Mende A, Kobayashi T, Kugiyama K: Low adiponectin 
levels predict late in-stent restenosis after bare metal stenting in native coronary arteries. Int J Cardiol 2008, 131:78-82.

27. Mito T, Miura S, Iwata A, Morii J, Sugihara M, Ike A, Mori K, Kawamura A, Nishikawa H, Zhang B, Saku K: Determination of the cut-off plasma adiponectin level associated with a lower risk of restenosis in patients with stable angina. Coron Artery Dis 2011, 22:451-457.

28. Hsieh CJ, Wang PW: Effect of cilostazol treatment on adiponectin and soluble CD40 ligand levels in diabetic patients with peripheral arterial occlusion disease. Circ J 2009, 73:948-954.

29. Sahebkar A, Watts GF: Fibrate therapy and circulating adiponectin concentrations: a systematic review and meta-analysis of randomized placebo-controlled trials. Atherosclerosis 2013, 230:110-120.

30. Cohen A, Rabbani A, Shah N, Alexander GC: Changes in glitazone use among office-based physicians in the U.S., 2003-2009. Diabetes Care 2010, 33:823-825.

31. Henriksen K, Byrjalsen I, Qvist P, Beck-Nielsen H, Hansen G, Riis BJ, Perrild H, Svendsen OL, Gram J, Karsdal MA, Christiansen C: Efficacy and safety of the PPARgamma partial agonist balaglitazone compared with pioglitazone and placebo: a phase III, randomized, parallel-group study in patients with type 2 diabetes on stable insulin therapy. Diabetes Metab Res Rev 2011, 27:392-401.

doi:10.1186/1471-2261-14-184

Cite this article as: Walker et al:: Retrospective review of superficial femoral artery stenting in diabetic patients: thiazolidinedione use may decrease reinterventions. BMC Cardiovascular Disorders 2014 14:184.

\section{Submit your next manuscript to BioMed Central and take full advantage of:}

- Convenient online submission

- Thorough peer review

- No space constraints or color figure charges

- Immediate publication on acceptance

- Inclusion in PubMed, CAS, Scopus and Google Scholar

- Research which is freely available for redistribution 